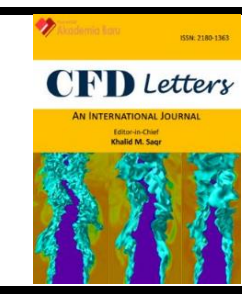

\title{
MHD and Slip Effect in Micropolar Hybrid Nanofluid and Heat Transfer over a Stretching Sheet with Thermal Radiation and Non-uniform Heat Source/Sink
}

\author{
Nur Faizzati Ahmad Faizal ${ }^{1}$, Norihan Md Ariffin ${ }^{1,2}$, Yong Faezah Rahim ${ }^{3,}{ }^{*}$, Mohd Ezad Hafidz \\ Hafidzuddin ${ }^{3}$, Nadihah Wahi ${ }^{1}$ \\ Department of Mathematics, Universiti Putra Malaysia, Serdang Selangor 43400 UPM, Malaysia \\ Institute for Mathematical Research, Universiti Putra Malaysia, Serdang Selangor 43400 UPM, Malaysia \\ Centre of Foundation Studies For Agricultural Science, Universiti Putra Malaysia, Serdang Selangor 43400 UPM, Malaysia
}

\section{ARTICLE INFO}

Article history:

Received 23 September 2020

Received in revised form 21 November 2020

Accepted 25 November 2020

Available online 30 November 2020

Keywords:

Hybrid nanofluid; micropolar fluid;

thermal radiation; suction;

Magnetohydrodynamic (MHD)

\section{ABSTRACT}

In the presence of slips, non-uniform heat source/sink, thermal radiation and magnetohydrodynamic (MHD), micropolar hybrid nanofluid and heat transfer over a stretching sheet has been studied. The problem is modelled as a mathematical formulation that involves a system of the partial differential equation. The similarity approach is adopted, and self-similar ordinary differential equations are obtained and then those are solved numerically using the shooting method. The flow field is affected by the presence of physical parameters such as micropolar parameter, magnetic field parameter, suction parameter and slip parameter whereas the temperature field is affected by thermal radiation parameter, space-dependent parameter, temperaturedependent internal heat generation/absorption parameter, Prantl number and Biot number. The skin friction coefficient, couple stress and local Nusselt number are tabulated and analysed. The effects of the governing parameters on the velocity profiles, angular velocity profiles and temperature profiles are illustrated graphically. The results of velocity profiles, angular velocity profiles and temperature profiles are also obtained for several values of each parameters involved. 
purpose. The main agenda of the current analysis is to present the behavior of emerging hybrid nanofluid in the presence of micropolar fluid theory and rotation over a stretching sheet. Eringen [1] was first introduced the micropolar theory and discussed it in detail in his research. A lot of researchers (see Ahmadi [2], El-Hakiem [3], Damseh et al., [4], Ishak [5], Das [6] and Naveed et al., [7]) started to studied and did an intensive investigation by extending Eringen's work by considering many aspects.

However, many other researchers have shift their interest and come out with different brilliant investigation with various type of hybrid nanoparticles using a new procreation of heat transfer fluid, which is hybrid nanofluid to give a better heat transfer outcome compared to traditional cooling fluid. Devi and Devi [8] were the first to analyse the boundary layer equations of hybrid nanofluid by introducing a new special form of thermophysical properties.

Suresh et al., [9] conducted a fully developed laminar convective heat transfer and pressure drop characteristics through a uniformly heated circular tube using $\mathrm{Al}_{2} \mathrm{O}_{3}-\mathrm{Cu} /$ water hybrid nanofluid. Besides, Momin [10] investigated the mixed convection laminar flow of hybrid nanofluid $\mathrm{Al}_{2} \mathrm{O}_{3}-$ $\mathrm{Cu} /$ water inside an inclined tube. Furthermore, there are many other researchers also focusing on different problems by hybrid different nanoparticles with different effects and fluids. Moreover, Subhani and Nadeem [11] conducted a numerical analysis of micropolar hybrid nanofluid and the outcome proved that the rate of heat transfer of hybrid nanofluid is higher than nanofluid even with various effects of parameter such as micropolar effect, rotation and porosity. Khashi'ie et al., [12] were focusing their studies on mixed convection stagnation point flow of hybrid nanofluid over a permeable stretching/shrinking cylinder with the presence of thermal stratification effect.

Inspired by all the previous literatures, the motivation of this studies is to investigate the effects of the slip-on hybrid micropolar nanofluid flow and heat transfer over a stretching sheet with thermal radiation, non-uniform heat source/sink and magnetohydrodynamic (MHD). The nonlinear ordinary differential equations obtained are solved numerically by shooting method. The effects of governing parameters on the skin friction coefficients, wall couple stress and local Nusselt number are investigated and analysed. We extended the Pal and Mandal [13] studies by adding the effect of the slip and MHD to their problem.

\section{Methodology}

We consider the steady two-dimensional flow of micropolar hybrid nanofluid past a stretching sheet in the presence of thermal radiation with slip, non-uniform heat source/sink and MHD as shown in Figure 1 . The fluid velocities are denoted by $u$ and $v$ which are measured in the $x-$ and $y-$ axes, respectively and magnetic field of intensity $B_{0}$ is along $y$ direction.

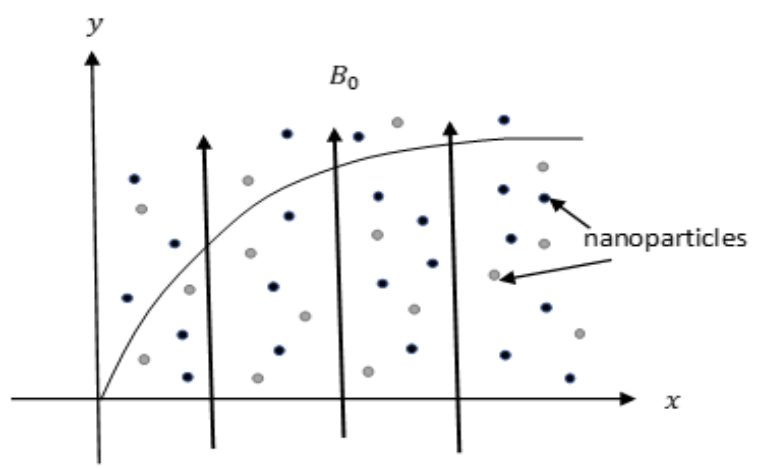

Fig. 1. Physical model with coordinate system for stretching sheet 
The steady state boundary layer equations for the propose problem in the Cartesian coordinates are given by:

$$
\begin{aligned}
& \frac{\partial u}{\partial x}+\frac{\partial v}{\partial y}=0 \\
& \rho_{h n f}\left(u \frac{\partial u}{\partial x}+v \frac{\partial u}{\partial y}\right)=\left(\mu_{h n f}+\kappa_{1}\right) \frac{\partial^{2} u}{\partial y^{2}}+\kappa_{1} \frac{\partial N}{\partial y}-\sigma_{h n f} B_{0}^{2} u \\
& \rho_{h n f} j\left(u \frac{\partial N}{\partial x}+v \frac{\partial N}{\partial y}\right)=-\kappa_{1}\left(2 N+\frac{\partial u}{\partial y}\right)+\gamma_{h n f}\left(\frac{\partial^{2} N}{\partial y^{2}}\right) \\
& u \frac{\partial T}{\partial x}+\frac{\partial T}{\partial y}=\alpha_{h n f} \frac{d^{2} T}{d y^{2}}-\frac{1}{\left(\rho C_{P}\right)_{h n f}} \frac{\partial q_{r}}{\partial y}-\frac{1}{\left(\rho C_{p}\right)_{h n f}} q^{\prime \prime \prime}
\end{aligned}
$$

subject to the following boundary conditions as given by (Ibrahim and Gadisa [14]):

$$
\begin{aligned}
& u=u_{w}(x)+L \frac{\partial u}{\partial y}, v=v_{w}, N=-m \frac{\partial u}{\partial y},-k \frac{\partial T}{\partial y}=h_{1}\left(T_{f}-T\right) \text { at } y=0, \\
& u \rightarrow 0, N \rightarrow 0, T \rightarrow T_{\infty} \text { as } y \rightarrow \infty .
\end{aligned}
$$

Here, $T$ is the fluid temperature, $N$ is the microrotation vector normal to $x y$-plane, $j$ is the microinertia density, $\kappa_{1}$ is the vortex viscosity(gyro-viscosity), $B_{0}$ is the strength of magnetic field, $\left(\rho C_{p}\right)_{h n f}$ is the heat capacitance in the hybrid nanofluid, $\mu_{h n f}$ is the dynamic viscosity of the hybrid nanofluid, $\rho_{h n f}$ is the density of the hybrid nanofluid, $\alpha_{h n f}$ is the thermal diffusivity of the hybrid nanofluid, $\sigma_{h n f}$ is the electrical conductivity in hybrid nanofluid, $\gamma_{h n f}$ is the spin gradient viscosity in hybrid nanofluid, $v_{w}$ is the constant flux velocity with $v_{w}<0$ for suction and $v_{w}>0$ for injection, $T_{f}$ is the convective fluid temperature and $h_{1}$ is the heat coefficient. It is assumed that the temperature at the stretching sheet takes the constant values $T_{w}$, while the temperature of the ambient nanofluid take the constant value $T_{\infty}$. These variables are mathematically defined as (Subhani and Nadeem [11]):

$$
\begin{aligned}
& \left(\rho C_{p}\right)_{h n f}=\phi_{2}\left(\rho C_{p}\right)_{s_{2}}+\left(1-\phi_{2}\right)\left[\left(1-\phi_{1}\right)\left(\rho C_{p}\right)_{f}+\phi_{1}\left(\rho C_{p}\right)_{s_{1}}\right] \\
& \mu_{h n f}=\frac{\mu_{f}}{\left(1-\phi_{1}\right)^{2.5}\left(1-\phi_{2}\right)^{2.5}}, \rho_{h n f}=\phi_{2} \rho_{s 2}+\left(1-\phi_{2}\right)\left[\left(1-\phi_{1}\right) \rho_{f}+\phi_{1} \rho_{s}\right] \\
& \sigma_{h n f}=\phi_{2} \sigma_{s 2}+\left(1-\phi_{2}\right)\left[\left(1-\phi_{1}\right) \sigma_{f}+\phi_{1} \sigma_{s}\right] \\
& \frac{k_{h n f}}{k_{n f}}=\frac{\left(k_{s_{2}}+2 k_{n f}\right)-2 \phi_{2}\left(k_{n f}-k_{s_{2}}\right)}{\left(k_{s_{2}}+2 k_{n f}\right)+\phi_{2}\left(k_{n f}-k_{s_{2}}\right)}, \frac{k_{n f}}{k}=\frac{\left(k_{s}+2 k_{f}\right)-2 \phi_{2}\left(k_{f}-k_{1}\right)}{\left(k_{s_{1}}+2 k_{f}\right)+\phi_{1}\left(k_{f}-k_{s_{1}}\right)} \\
& \alpha_{h n f}=\frac{k_{h n f}}{\left(\rho C_{p}\right)}
\end{aligned}
$$

We note that $m$ is a constant such that $0 \leq m \leq 1$. It is noted that $m=0$ indicates $N=0$ which is no-spin condition. The case $m=1 / 2$ represents the weak concentration of microelements. The case corresponding to $m=1$ is used for the modelling of turbulent flows. Now regarding the approximation of Rosseland for radiation according to Bhattacharyya et al., [15], the radiative heat flux is simplified as $q_{r}=\left(4 \sigma^{*} / 3 k^{*}\right) \partial T^{4} / \partial y$, where $\sigma^{*}$ is the Stefan-Boltzman constant, $k^{*}$ is the absorption coefficient.

The $q^{\prime \prime \prime}$ is the non-uniform heat source/sink modelled as (Pal and Chatterjee [16]): 


$$
q^{\prime \prime \prime}=\left(\frac{\kappa_{h n f} u_{w}(x)}{x v_{f}}\right)\left[A^{*}\left(T_{w}-T_{\infty}\right) F^{\prime}(\eta)+\left(T-T_{\infty}\right) B^{*}\right.
$$

where $A^{*}$ and $B^{*}$ represent the space dependant and temperature dependent internal generation or absorption parameters respectively. If the case $A^{*}<0$ and $B^{*}<0$, it shows that the case corresponds to internal heat absorption otherwise if the case $A^{*}>0$ and $B^{*}>0$, it shows that the case corresponds to internal heat generation.

The following dimensionless variables are introduced as follows:

$$
\eta=(c v)^{\frac{1}{2}} y, \psi=(c v)^{\frac{1}{2}} x f(\eta), N=c x\left(\frac{c}{v}\right)^{\frac{1}{2}} h(\eta), \theta(\eta)=\frac{T-T_{\infty}}{T_{w}-T_{\infty}}
$$

where $\eta$ is the similarity variable and $\psi$ is the stream function defined in the usual way to identically satisfied Eq. (1) as $u=\frac{\partial \psi}{\partial y}$ and $v=-\frac{\partial \psi}{\partial x}$.

By substituting Eqs. (5) - (8) into Eqs. (2) - (4) along with boundary conditions Eqs. (5) and (6) are then transform into the following nonlinear ordinary differential equations obtained as

$$
\begin{aligned}
& \frac{1}{\phi_{2}}\left(\phi_{1}+K\right) f^{\prime \prime \prime}-\frac{\phi_{4}}{\phi_{2}} M f^{\prime}+f f^{\prime \prime}-f^{\prime 2}+\frac{1}{\phi_{2}} K h^{\prime}=0 \\
& \frac{K}{\phi_{2}}\left(2 h+f^{\prime \prime}\right)-\frac{1}{\phi_{2}}\left(-\phi_{1}-\frac{K}{2}\right) h^{\prime \prime}+f h^{\prime}-f^{\prime} h=0 \\
& \frac{k_{h n f}}{P r k_{f}}+\frac{N r}{\operatorname{Pr}}\left\{1-\left(1+\theta_{w}\right) \theta\right\}^{3} \theta^{\prime \prime}-\frac{1}{\operatorname{Pr}}\left(A^{*} f^{\prime}+B^{*} \theta\right)+\phi_{3} f \theta^{\prime}=0
\end{aligned}
$$

subject to boundary conditions

$$
\begin{aligned}
& f(\eta)=S, f^{\prime}(\eta)=1+\alpha f^{\prime \prime}(0), h(\eta)=-m f^{\prime \prime}(\eta), \theta(\eta)=\left(\frac{\theta^{\prime}(0)}{\gamma}+1\right) \text { at } \eta=0, \\
& f^{\prime}(\eta) \rightarrow 0, h(\eta) \rightarrow 0, \theta(\eta) \rightarrow 0 \text { as } \eta \rightarrow \infty
\end{aligned}
$$

where differentiation with respect to $\eta$ is signified by $\left({ }^{\prime}\right), \operatorname{Pr}=\frac{v_{f}}{a_{f}}$ is the Prandtl number and $K=$ $\frac{k_{1}}{\mu_{f}}$ is the material/micropolar parameter, $S=-v_{w} /(a v)^{1 / 2}$ is the constant flux parameter with $S>0$ corresponds to suction and $S<0$ corresponds to injection, $M=\frac{\sigma_{f}}{c \rho_{f}} B_{0}^{2}$ is the magnetic field, $N r=-\frac{16 \sigma^{*} T_{\infty}^{3}}{3_{\kappa_{f}} K^{*}}$ is thermal radiation parameter, $\alpha$ is velocity slip parameter and $\gamma$ is Biot number. We also have (see Pal and Mandal [16]):

$$
\begin{aligned}
& \theta_{1}=(1-\theta)^{2.5}, \theta_{2}=1-\phi+\phi\left(\frac{\rho_{s}}{\rho_{f}}\right), \theta_{3}=1-\phi+\frac{\left(\rho C_{P}\right)_{s}}{\left(\rho C_{P}\right)_{f}} \\
& \theta_{4}=1-\phi+\phi\left(\frac{\sigma_{s}}{\sigma_{f}}\right) .
\end{aligned}
$$




\section{Results and Discussion}

The nonlinear ordinary differential equations, Eqs. (10)-(12) which are subjected to the boundary conditions Eqs. (13) and (14) are solved numerically using shooting method. Numerical solutions for the effects of partial slip on boundary layer flow in micropolar fluid in the presence of thermal radiation, non-uniform heat source/sink and MHD are reported in this section. The values of the skinfriction coefficient, wall couple stress coefficient and local Nusselt number for various governing parameters are obtained. Table 1 shows the thermophysical properties of base fluid and nanoparticles. We have considered water as the fluid base and the nanoparticle are $\mathrm{Cu}$ and $\mathrm{Al}_{2} \mathrm{O}_{3}$. Table 2 shows the computed values of skin friction coefficient $f^{\prime \prime}(0)$, couple stress $-h^{\prime}(0)$ and local Nusselt number $-\theta^{\prime}(0)$ for $\mathrm{Cu}-\mathrm{Al}_{2} \mathrm{O}_{3}$ /water with different values of suction/injection parameter $S$ and velocity slip parameter $\alpha$. It is found that $f^{\prime \prime}(0),-h^{\prime}(0)$ and $-\theta^{\prime}(0)$ are decreases with increasing $S$. The effect of Biot number, $\gamma$ for different values of suction/injection parameter is given in Table 3. It shows that the heat transfer rate is a increasing function of $\gamma$. Numerical values of skin friction coefficient $f^{\prime \prime}(0)$, couple stress $-h^{\prime}(0)$, and local Nusselt number $-\theta^{\prime}(0)$ with different values of micropolar parameter $K$ is given in table 4 and it is clear from this table, the values of $f^{\prime \prime}(0)$, $-h^{\prime}(0)$, and $-\theta^{\prime}(0)$ increases with increasing $K$.

Table 1

Thermophysical properties of base fluid and nanoparticles

\begin{tabular}{llll}
\hline Physical properties & Fluid phase (water) & $\mathrm{Cu}$ & $\mathrm{Al}_{2} \mathrm{O}_{3}$ \\
\hline$C_{\rho}(\mathrm{J} / \mathrm{kgK})$ & 4179 & 385 & 765 \\
$\rho\left(\mathrm{kg} / \mathrm{m}^{3}\right)$ & 997.1 & 8933 & 3970 \\
$\kappa(\mathrm{W} / \mathrm{mK})$ & 0.613 & 400 & 40 \\
$\sigma(\mathrm{S} / \mathrm{m})$ & $5.5 \times 10^{-6}$ & $5.9 \times 10^{6}$ & $35 \times 10^{6}$ \\
\hline
\end{tabular}

Figures 2 to 4 show the variations of skin friction coefficient, couple stress coefficient and local Nusselt number with $S$ for various values of velocity slip, $\alpha$. All variations show that it is decreases with $S$ and increases with $\alpha$. The variations of local Nusselt number with $S$ for various values of Biot number, $\gamma$ is depicted in Figure 5. The variation is found increase with an increase in $S$. Temperature distribution which results in enhancement of local Nusselt number is due to physically increment both values of slip parameter, $\alpha$ and Biot number, $\gamma$. Profiles for velocity, angular velocity and temperature distribution are plotted in Figures 6 to 8 for different values of velocity slip, $\alpha$. It is noticed that, velocity profile decreases with increase $\alpha$. However, the angular velocity profile and temperature profile shown in Figures 7 and 8 increases with increase $\alpha$. This is due to increasing the velocity slip parameter and the portrayed that the boundary layer thickness also increase. Figure 9 is the plot of temperature profile for various values of Biot number, $\gamma$ and it is shows that the temperature profile increases with increase $\gamma$. The increment shows in the temperature profile in Figures 8 and 9 proved that the results in enhancement of temperature distribution due to strong heat transfer coefficient with the increases in both parameters. 


\section{Table 2}

Numerical values of of $f^{\prime \prime}(0),-h^{\prime}(0)$, and $-\theta^{\prime}(0)$ for $\mathrm{Cu}-\mathrm{Al}_{2} \mathrm{O}_{3}$ /water with different values of $\alpha$ when $A^{*}=B^{*}=\theta_{w}=1.2, n=0.1, \gamma=0.1, \phi=$ $0.01, M=2.0 \times 10^{-12}, \mathrm{Nr}=0.5, \mathrm{~K}=0.1, \mathrm{Pr}=6.8$

\begin{tabular}{lllll}
\hline$S$ & $\alpha$ & $f^{\prime \prime}(0)$ & $-h^{\prime}(0)$ & $-\theta^{\prime}(0)$ \\
\hline-0.1651 & 0.4 & 0.4260 & 0.1661 & 0.1020 \\
-0.0651 & & 0.2857 & 0.1481 & 0.1022 \\
0.0349 & & 0.1575 & 0.1340 & 0.1020 \\
0.1349 & & 0.0400 & 0.1234 & 0.1018 \\
0.2349 & & -0.0678 & 0.1159 & 0.1015 \\
\hline-0.1939 & 0.5 & 0.4822 & 0.1766 & 0.1019 \\
-0.0939 & & 0.3302 & 0.1558 & 0.1022 \\
0.0061 & & 0.1944 & 0.1394 & 0.1021 \\
0.1061 & & 0.0725 & 0.1267 & 0.1019 \\
0.2061 & & -0.0372 & 0.1175 & 0.1017 \\
\hline-0.1861 & 0.6 & 0.4830 & 0.1797 & 0.1021 \\
-0.0861 & & 0.3242 & 0.1573 & 0.1023 \\
0.0139 & & 0.1854 & 0.1398 & 0.1021 \\
0.1139 & & 0.0632 & 0.1264 & 0.1019 \\
0.2139 & & -0.0447 & 0.1165 & 0.1016 \\
\hline
\end{tabular}

\section{Table 3}

Numerical values of $-\theta^{\prime}(0)$ with different values $\gamma$ when $A^{*}=$ $B^{*}=\theta_{w}=1.2, n=0.1, \phi=0.01, \mathrm{M}=2.0 \times 10^{-12}, \mathrm{Nr}=0.5, \alpha=$ $0.1, K=0.1, \operatorname{Pr}=6.8$

\begin{tabular}{lll}
\hline$S$ & $\gamma$ & $-\theta^{\prime}(0)$ \\
\hline-0.1059 & 0.4 & 0.3682 \\
-0.0059 & & 0.3830 \\
0.0941 & & 0.3902 \\
0.1941 & & 0.3939 \\
0.2941 & 0.5 & 0.3959 \\
\hline-0.1059 & & 0.4457 \\
-0.0059 & & 0.4691 \\
0.0941 & & 0.4809 \\
0.1941 & 0.6 & 0.4872 \\
0.2941 & & 0.4909 \\
\hline-0.1059 & & 0.5185 \\
-0.0059 & & 0.5517 \\
0.0941 & & 0.5691 \\
0.1941 & & 0.5787 \\
0.2941 & & 0.5843 \\
\hline
\end{tabular}

The variations of skin friction coefficient, couple stress coefficient and local Nusselt number with $S$ for various values of material/micropolar parameter, $K$ are plotted in Figures 10 to 12 . All variations show that it is increases with $S$ and increases with $K$. Physically, this is due to the material parameter supports the particles of the skew-symmetric of the fluid and therefore the couple stress coefficient increases. Figures 13 to 15 show the velocity profile, angular velocity profile and temperature profile for various values of material/micropolar parameter, $K$, respectively. As observed in Figures 13 and 14, the velocity profile and the angular velocity profile increases with increasing of micropolar parameter, $K$. Physically, this enhancement in the thickness of the momentum boundary layer indicates that the micropolar parameter produces less drag force in the boundary layer separation. From Figure 15, it is observed that the temperature profile decreases with increase material/micropolar parameter, $K$. 


\section{Table 4}

Numerical values of $-\theta^{\prime}(0)$ with different values $\gamma$ when $A^{*}=B^{*}=\theta_{w}=1.2$, $n=0.1, \phi=0.01, \mathrm{M}=2.0 \times 10^{-12}, \mathrm{Nr}=0.5, \alpha=0.1, K=0.1, \operatorname{Pr}=6.8$

\begin{tabular}{lllll}
\hline$S$ & $K$ & $f^{\prime \prime}(0)$ & $-h^{\prime}(0)$ & $-\theta^{\prime}(0)$ \\
\hline 0.2500 & 0.2 & -0.0144 & 0.3166 & 0.1017 \\
0.3500 & & -0.1235 & 0.2958 & 0.1015 \\
0.4500 & -0.2289 & 0.2795 & 0.1013 \\
0.5500 & & -0.3307 & 0.2675 & 0.1011 \\
0.6500 & & -0.4288 & 0.2598 & 0.1010 \\
\hline 0.1959 & 0.3 & 0.2265 & 0.7691 & 0.1020 \\
0.2959 & & 0.1027 & 0.7028 & 0.1018 \\
0.3959 & & -0.0173 & 0.6418 & 0.1016 \\
0.4959 & & -0.1333 & 0.5865 & 0.1014 \\
0.5959 & & -0.2451 & 0.5376 & 0.1012 \\
\hline 0.0279 & 0.7827 & 1.7433 & 0.1026 \\
0.1279 & 0.4 & 0.6360 & 1.6140 & 0.1024 \\
0.2279 & & 0.4929 & 1.4900 & 0.1022 \\
0.3279 & & 0.3534 & 1.3714 & 0.1019 \\
0.4279 & & 0.2174 & 1.2582 & 0.1017 \\
\hline
\end{tabular}

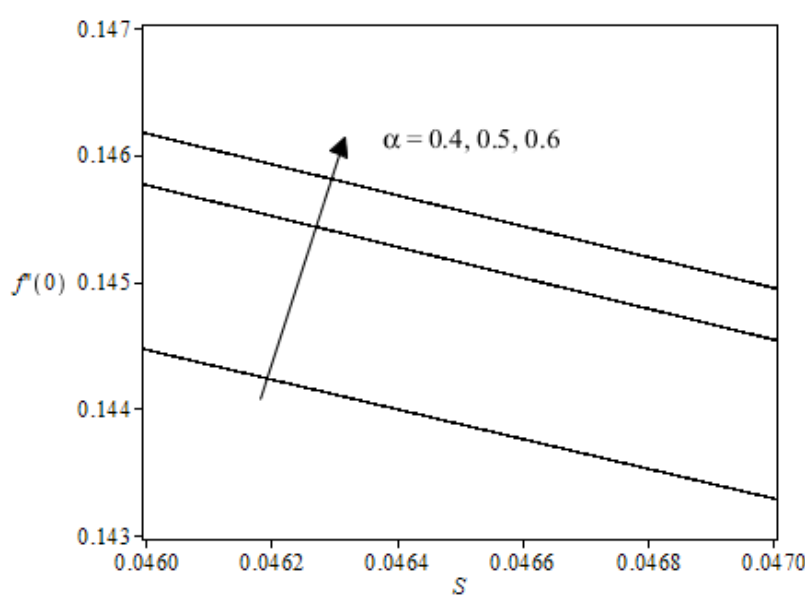

Fig. 2. Skin friction coefficient with $S$ for different values of $\alpha$

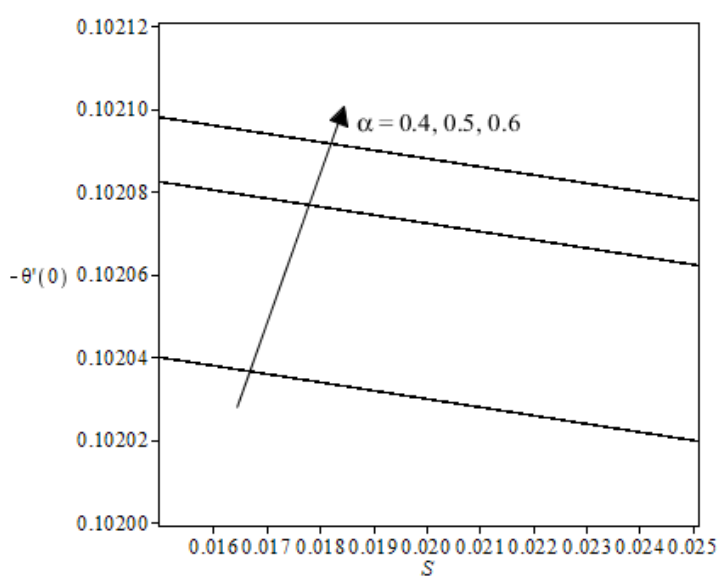

Fig. 4. Local Nusselt number with $S$ for different values of $\alpha$

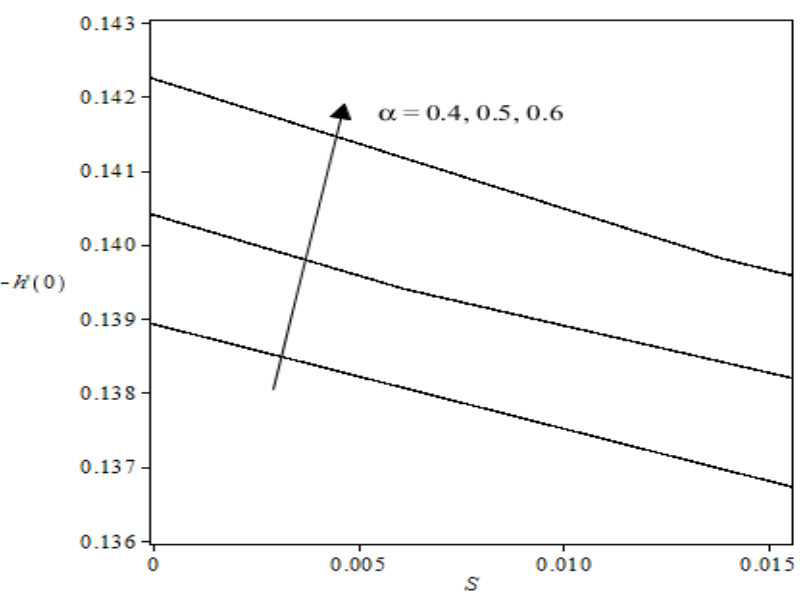

Fig. 3. Couple stress with $S$ for different values of $\alpha$

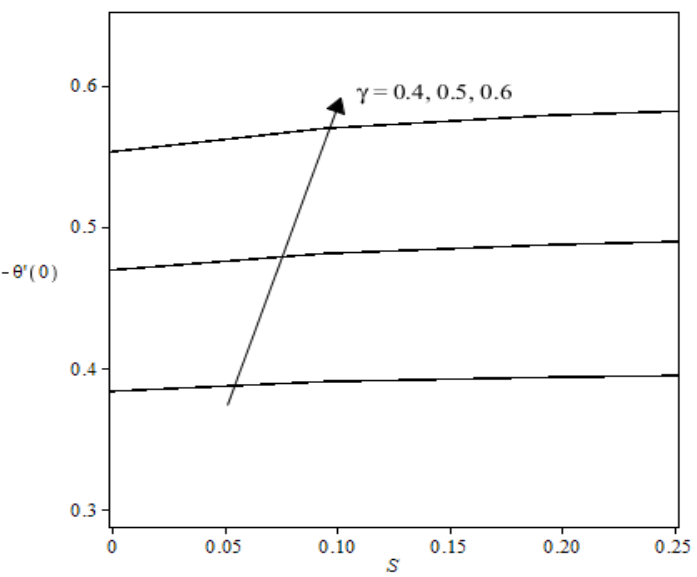

Fig. 5. Local Nusselt number with $S$ for different values of $\gamma$ 


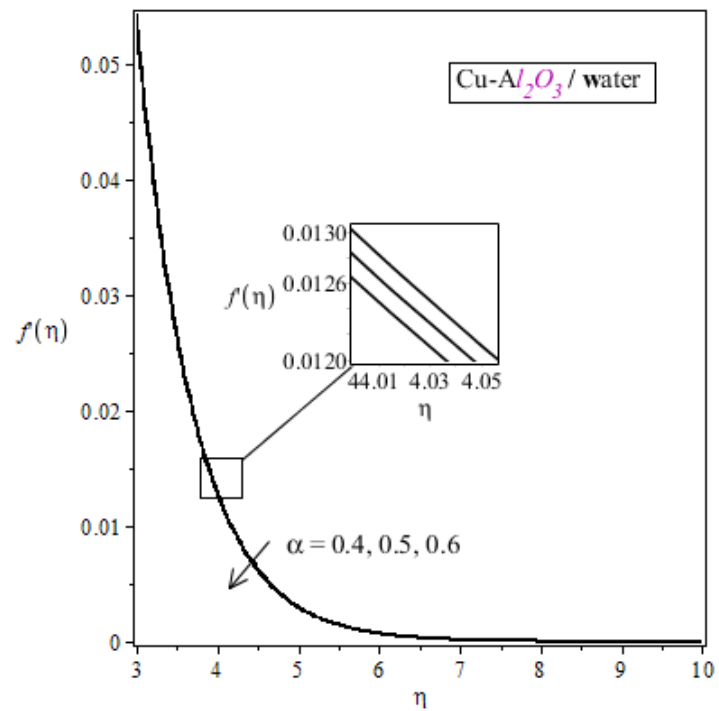

Fig. 6. Velocity profile for several values of $\alpha$

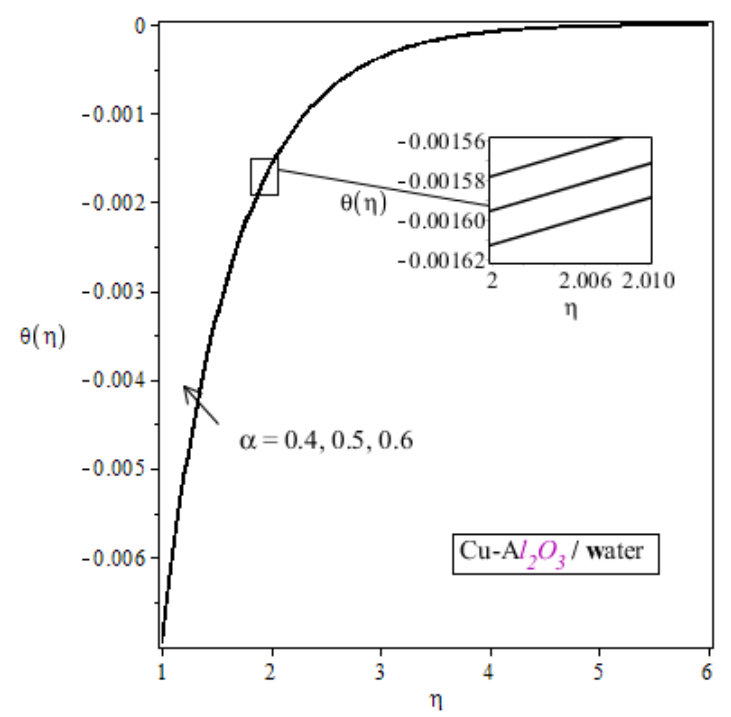

Fig. 8. Temperature profile for several values of $\alpha$

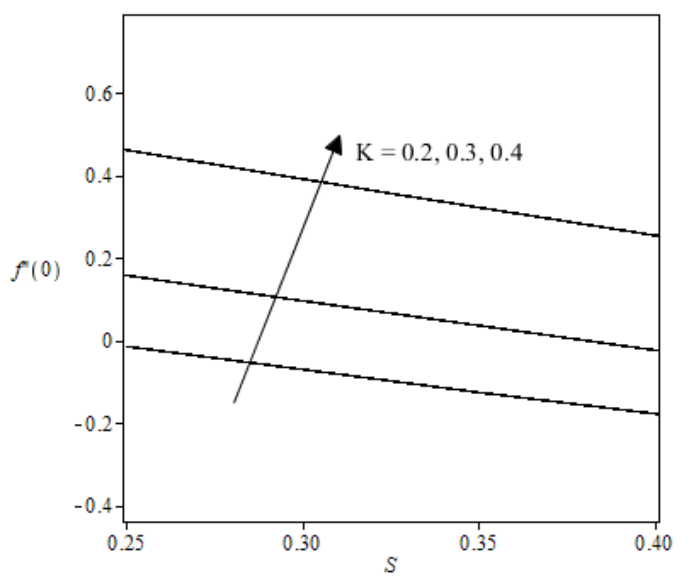

Fig. 10. Skin friction coefficient with $S$ for different values of $K$

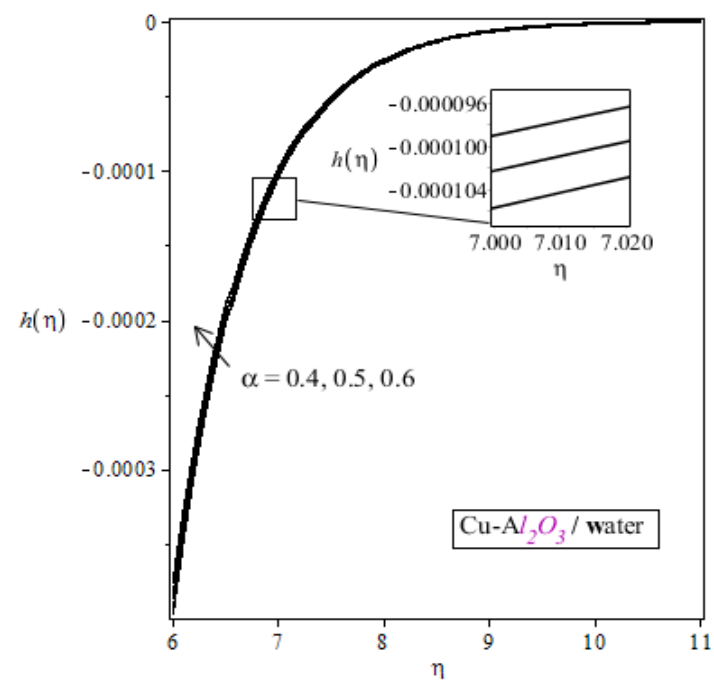

Fig. 7. Angular velocity profile for several values of $\alpha$

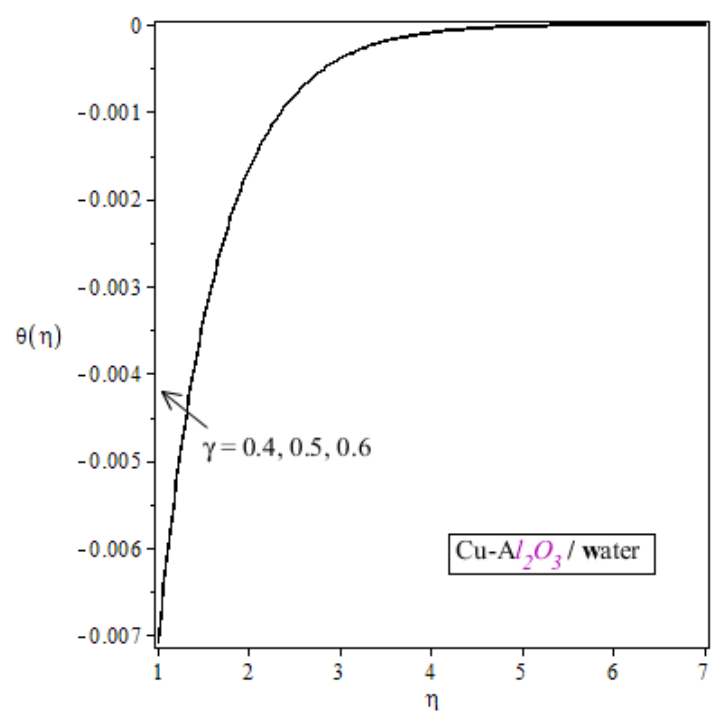

Fig. 9. Temperature profile for several values of $\gamma$

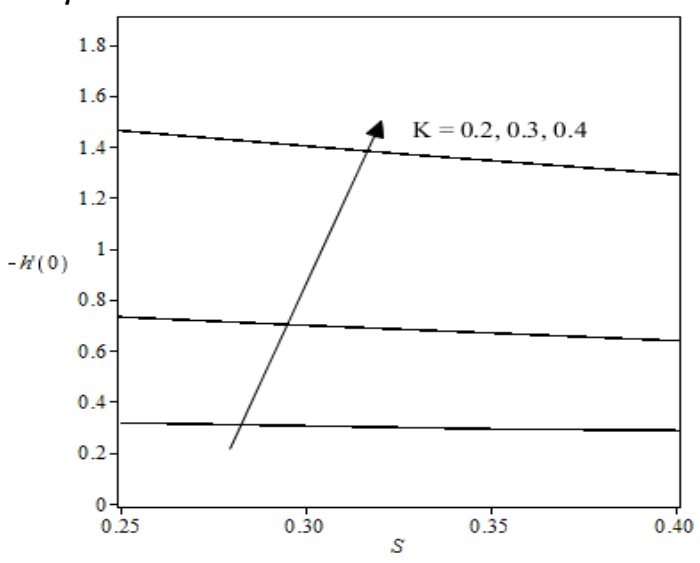

Fig. 11. Couple stress with $S$ for different values of $K$ 


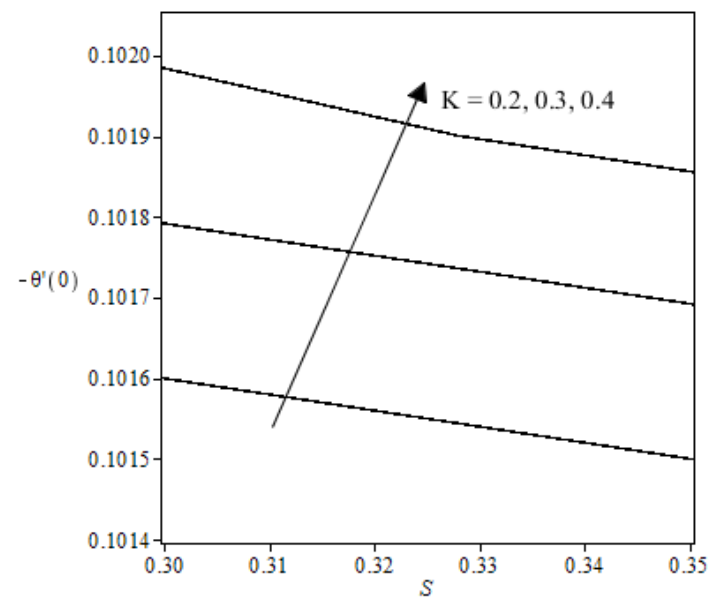

Fig. 12. Local Nusselt number with $S$ for different values of $K$

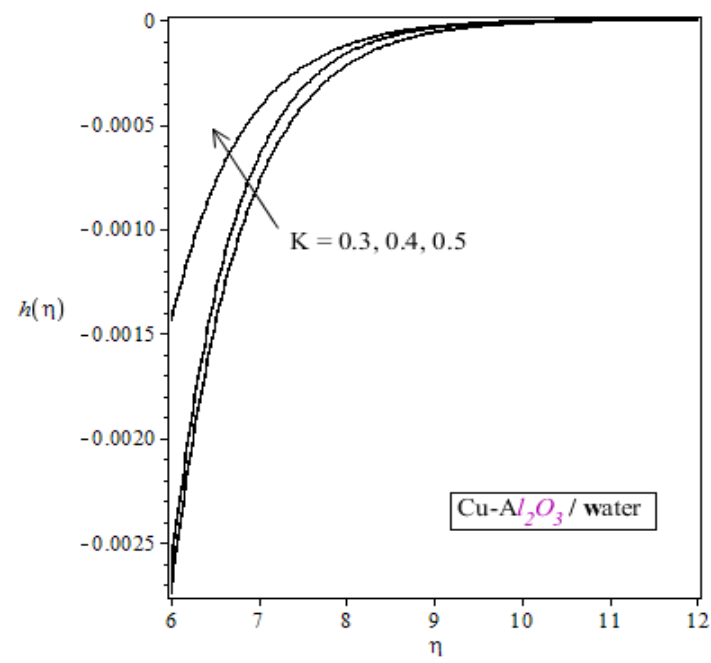

Fig. 14. Angular velocity profile for several values of $K$

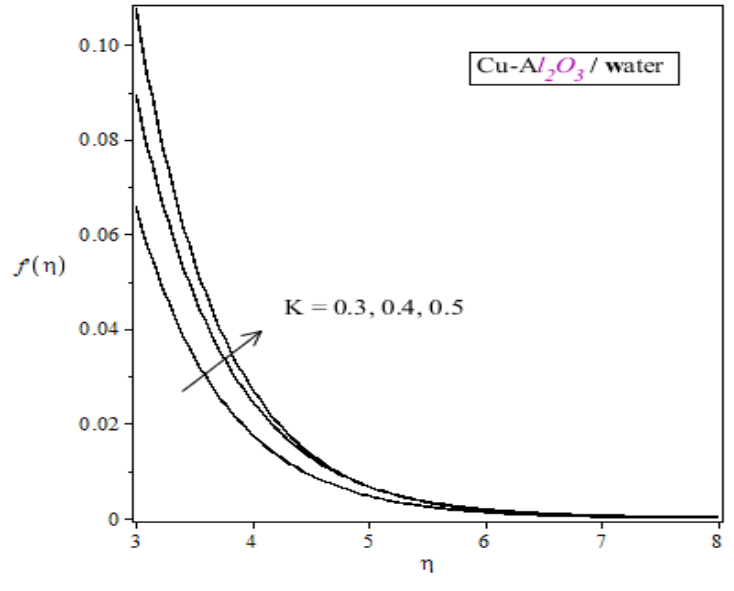

Fig. 13. Velocity profile for several values of K

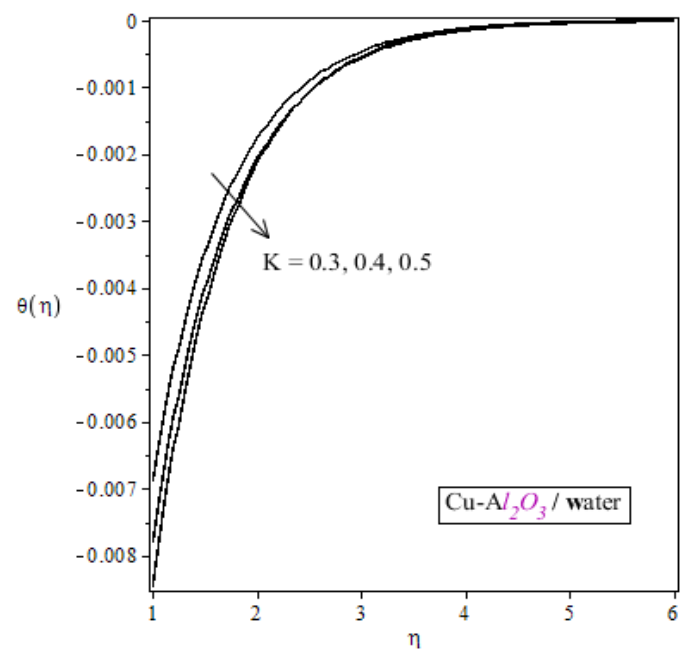

Fig. 15. Temperature profile for several values of $K$

\section{Conclusions}

In the present work, the effects of velocity slip on MHD micropolar hybrid nanofluid over a stretching sheet with thermal radiation and non-uniform heat source/sink have been studied. The resulting partial differential equations, which describe the problem, are transformed into ordinary differential equations by using similarity transformations and the shooting method was implemented to get the solutions. Profiles for velocity, angular velocity and temperature are obtained for different values of the governing parameter involved. The results show that the skin friction and couple stress increase as the slip parameter, $\alpha$ increase. This bring to the increases the thickness of boundary layer as increasing slip parameter, $\alpha$. Furthermore, the heat transfer coefficient increases as the velocity slip parameter $\alpha$ and Biot number $\gamma$ increases. This causes the increase of thermal layer thickness as both values of slip parameter, $\alpha$ and biot number, $\gamma$ increases. The angular velocity of the micropolar fluid increased for the higher values of material and slip parameters. 


\section{Acknowledgement}

The financial support through the Fundamental Research Grant Scheme (FRGS)-5540309 from Ministry of Education (Malaysia) are appreciatively acknowledged.

\section{References}

[1] Eringen, Ahmed Cemal. "Theory of micropolar fluid." Journal of Mathematics and Mechanics, 16 (1966): 1-18. https://doi.org/10.1512/iumj.1967.16.16001

[2] Ahmadi, Goodarz. "Self-similar solution of imcompressible micropolar boundary layer flow over a semi-infinite plate." International Journal of Engineering Science 14, no. 7 (1976): 639-646. https://doi.org/10.1016/0020-7225(76)90006-9

[3] El-Hakiem, M. A. "Natural convection in a micropolar fluid with thermal dispersion and internal heat generation." International communications in heat and mass transfer 31, no. 8 (2004): 1177-1186. https://doi.org/10.1016/j.icheatmasstransfer.2004.08.015

[4] Damseh, Rebhi A., M. Q. Al-Odat, Ali J. Chamkha, and Benbella A. Shannak. "Combined effect of heat generation or absorption and first-order chemical reaction on micropolar fluid flows over a uniformly stretched permeable surface." International Journal of Thermal Sciences 48, no. 8 (2009): 1658-1663.

https://doi.org/10.1016/j.ijthermalsci.2008.12.018

[5] Ishak, Anuar. "Thermal boundary layer flow over a stretching sheet in a micropolar fluid with radiation effect." Meccanica 45, no. 3 (2010): 367-373.

https://doi.org/10.1007/s11012-009-9257-4

[6] Das, Kalidas. "Influence of thermophoresis and chemical reaction on MHD micropolar fluid flow with variable fluid properties." International journal of heat and mass transfer 55, no. 23-24 (2012): 7166-7174.

https://doi.org/10.1016/i.ijheatmasstransfer.2012.07.033

[7] Naveed, M., Z. Abbas, and M. Sajid. "MHD Flow of Micropolar Fluid due to a Curved Stretching Sheet with Thermal Radiation." Journal of Applied Fluid Mechanics 9, no. 1 (2016). https://doi.org/10.18869/acadpub.jafm.68.224.23967

[8] Devi, SP Anjali, and S. Suriya Uma Devi. "Numerical investigation of hydromagnetic hybrid Cu-Al2O3/water nanofluid flow over a permeable stretching sheet with suction." International Journal of Nonlinear Sciences and Numerical Simulation 17, no. 5 (2016): 249-257.

https://doi.org/10.1515/ijnsns-2016-0037

[9] Suresh, S., K. P. Venkitaraj, P. Selvakumar, and M. Chandrasekar. "Effect of Al2O3-Cu/water hybrid nanofluid in heat transfer." Experimental Thermal and Fluid Science 38 (2012): 54-60. https://doi.org/10.1016/j.expthermflusci.2011.11.007

[10] Momin, Gaffar G. "Experimental investigation of mixed convection with water-AI2O3 \& hybrid nanofluid in inclined tube for laminar flow." Int. J. Sci. Technol. Res 2 (2013): 195-202.

[11] Subhani, Maryam, and Sohail Nadeem. "Numerical analysis of micropolar hybrid nanofluid." Applied Nanoscience 9 , no. 4 (2019): 447-459. https://doi.org/10.1007/s13204-018-0926-2

[12] Khashi'ie, Najiyah Safwa, Norihan Md Arifin, Ezad Hafidz Hafidzuddin, and Nadihah Wahi. "Stagnation Point Flow of Hybrid Nanofluid over a Permeable Vertical Stretching/Shrinking Cylinder with Thermal Stratification Effect. " CFD Letters 12, no. 2 (2020): 80-94.

[13] Pal, Dulal, and Gopinath Mandal. "Thermal radiation and MHD effects on boundary layer flow of micropolar nanofluid past a stretching sheet with non-uniform heat source/sink." International Journal of Mechanical Sciences 126 (2017): 308-318. https://doi.org/10.1016/j.ijmecsci.2016.12.023

[14] Ibrahim, Wubshet, and Gosa Gadisa. "Finite element analysis of couple stress micropolar nanofluid flow by nonFourier's law heat flux model past stretching surface." Heat Transfer-Asian Research 48, no. 8 (2019): $3763-3789$. https://doi.org/10.1002/htj.21567

[15] Bhattacharyya, Krishnendu, Swati Mukhopadhyay, G. C. Layek, and Ioan Pop. "Effects of thermal radiation on micropolar fluid flow and heat transfer over a porous shrinking sheet." International Journal of Heat and Mass Transfer 55, no. 11-12 (2012): 2945-2952.

https://doi.org/10.1016/j.ijheatmasstransfer.2012.01.051

[16] Pal, Dulal, and Sewli Chatterjee. "Heat and mass transfer in MHD non-Darcian flow of a micropolar fluid over a stretching sheet embedded in a porous media with non-uniform heat source and thermal radiation." Communications in Nonlinear Science and Numerical Simulation 15, no. 7 (2010): 1843-1857. https://doi.org/10.1016/i.cnsns.2009.07.024 